\title{
Melaleuca Snout Beetle, Melaleuca Weevil (unofficial common names), Oxyops vitiosa (Pascoe) (Insecta: Coleoptera: Curculionidae) ${ }^{1}$
}

\author{
J. P. Cuda, S. A. Wineriter, G. R. Buckingham, T. D. Center and K. T. Gioeli ${ }^{2}$

\section{Introduction}

\section{Life Cycle}

Melaleuca, Melaleuca quinquenervia (Cav.) S.T. Blake (Myrtaceae), is an invasive woody plant that is native to Australia, New Guinea, and the Soloman Islands. Melaleuca, also known as the paper bark tree, cajeput, punk tree, or white bottlebrush tree, was introduced into Florida in the late 19th century but apparently failed to naturalize until 1906. It was planted extensively as an ornamental, and eventually invaded suitable forested and non-forested wetland habitats in south Florida forming dense monocultures.

\section{Distribution}

The melaleuca weevil is native to Australia. This insect was released in Florida in 1997 after Australian field studies and laboratory testing demonstrated the weevil would reproduce only on melaleuca.

Establishment of the weevil has been confirmed in seven south Florida counties, including Broward, Collier, Dade, Glades, Lee, Palm Beach and St. Lucie.
Adults feed and reproduce on the leaves and shoots of saplings as well as the new growth of mature melaleuca trees. Females begin to produce eggs when they are approximately six weeks old and can live up to 10 months. They will deposit up to nine eggs per day and produce from 500 to 1000 eggs during their lives. The egg stage lasts approximately seven days, and larvae begin to feed immediately upon hatching. Larvae will complete their development in approximately seven weeks and migrate down the stems as they mature. When the larvae become prepupae (cease feeding), they crawl or drop to the ground to complete their development to the adult stage. The larvae will select a suitable site underground to form a pupal capsule from the surrounding soil. The insects will remain in the pupal stage for approximately two to six weeks but usually four weeks. Based on laboratory studies, development from the egg to the adult stage occurs in approximately 12 weeks. In south Florida, new adults

1. This document is EENY-211 (originally published as DPI Entomology Circular 410- updated for this publication), one of a series of Featured Creatures from the Entomology and Nematology Department, Florida Cooperative Extension Service, Institute of Food and Agricultural Sciences, University of Florida. Published: August 2003. Revised: July 2004. This document is also available on Featured Creatures Website at http://creatures.ifas.ufl.edu. Please visit the EDIS Website at http://edis.ifas.ufl.edu.

2. J. P. Cuda, assistant professor, Entomology and Nematology Department, University of Florida; S. A. Wineriter, and G. R. Buckingham, USDA, Gainesville, FL; T. D. Center, research entomologist, USDA Agricultural Research Service, Invasive Plant Research Laboratory, Fort Lauderdale, FL; and K. T. Gioeli.

The Institute of Food and Agricultural Sciences (IFAS) is an Equal Opportunity Institution authorized to provide research, educational information and other services only to individuals and institutions that function with non-discrimination with respect to race, creed, color, religion, age, disability, sex, sexual orientation, marital status, national origin, political opinions or affiliations. U.S. Department of Agriculture, Cooperative Extension Service, University of Florida, IFAS, Florida A. \& M. University Cooperative Extension Program, and Boards of County Commissioners Cooperating. Larry Arrington, Dean 


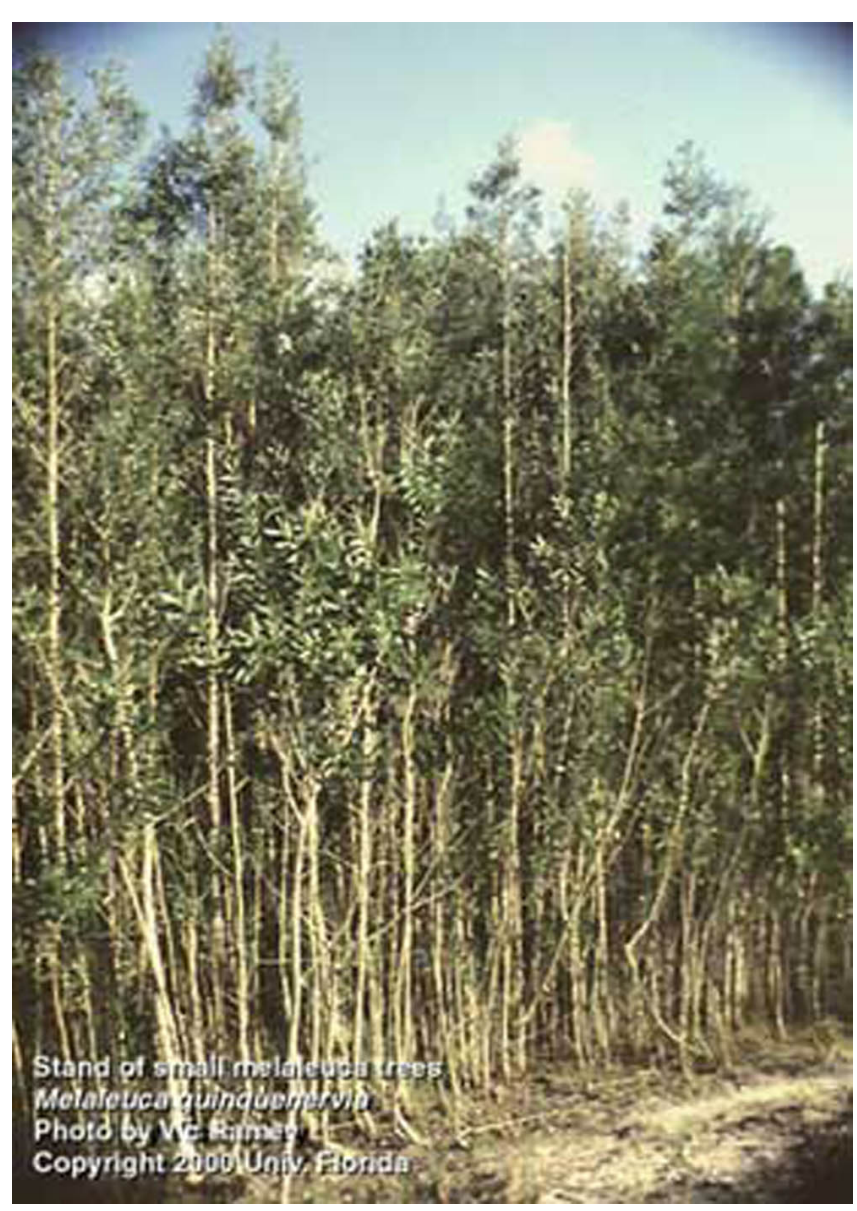

Figure 1. Stand of young melaleuca trees, Melaleuca quinquenervia (Cav.) S.T. Blake (Myrtaceae), in South Florida. Credits: V. Ramey, University of Florida

appeared in the field three months after the weevil was initially released, which suggests the melaleuca weevil is able to produce two to three generations per year in Florida's subtropical climate.

As mentioned previously, part of the life cycle of the melaleuca weevil occurs in the soil. While soil type does not appear to preclude establishment, pupation success may be higher at sites with sandy soils. Field and laboratory studies indicate the larvae can pupate under soil conditions ranging from saturated to drier areas with a high relative humidity. However, habitats in south Florida that are characterized by infrequent flooding, moderate melaleuca densities, and dry winters favor weevil establishment. Failure of the weevil to establish at permanently flooded sites suggests these conditions are not conducive to normal pupation, probably because submersed pupae cannot survive without oxygen for any length of time
Larvae are commonly observed on melaleuca plants in south Florida from October to May, which coincides with flushes of new leaf growth. Adults are present only during the summer months unless the melaleuca is mowed or otherwise damaged. Any activity that stimulates new leaf growth (e.g., shoot regrowth from cut stumps, damaged branches, root suckering, etc.) will support larval populations year-round at a specific site.

\section{Adult}

Melaleuca weevils are small, gray and 6 to $9 \mathrm{~mm}$ in length. Males are usually smaller than females. The adults are somewhat cryptic in appearance, but are usually found on the leaves and stems of saplings, or the new growth of older trees where they feed, mate and deposit their eggs. The presence of adults is usually indicated by the characteristic feeding damage that consists of holes or gouges chewed into the buds, leaves and stems. Occasionally, young shoot tips are nearly excised when stem feeding occurs on the tender new growth.

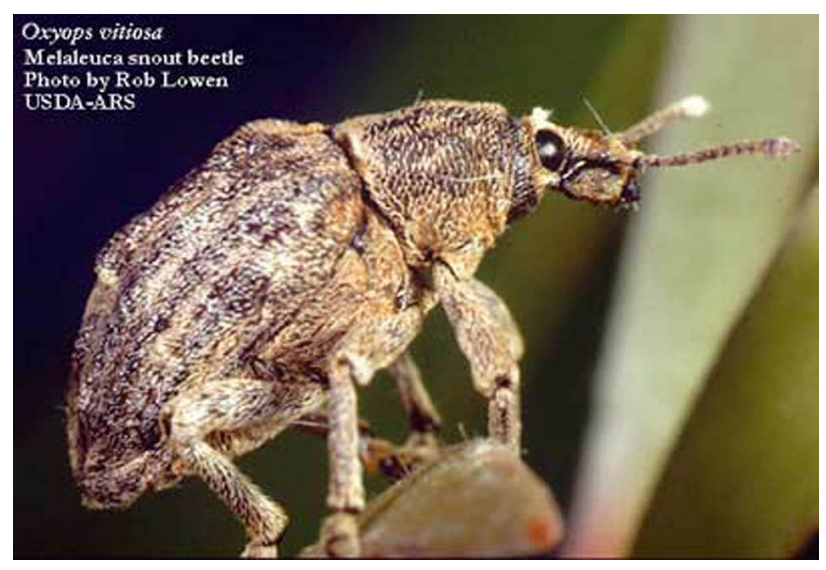

Figure 2. Adult melaleuca weevil, Oxyops vitiosa (Pascoe), on melaleuca leaf. Credits: K. Gioeli, University of Florida

\section{Egg}

The eggs of the melaleuca weevil are yellow, $1 \mathrm{~mm}$ long and resemble gel capsules. The female almost always covers the eggs in a secretion as soon as they are deposited to protect them from desiccation or predation. This secretion dries to form a hard protective casing, which is brown to black in color. When the eggs are present, they are usually associated with adult feeding damage. 


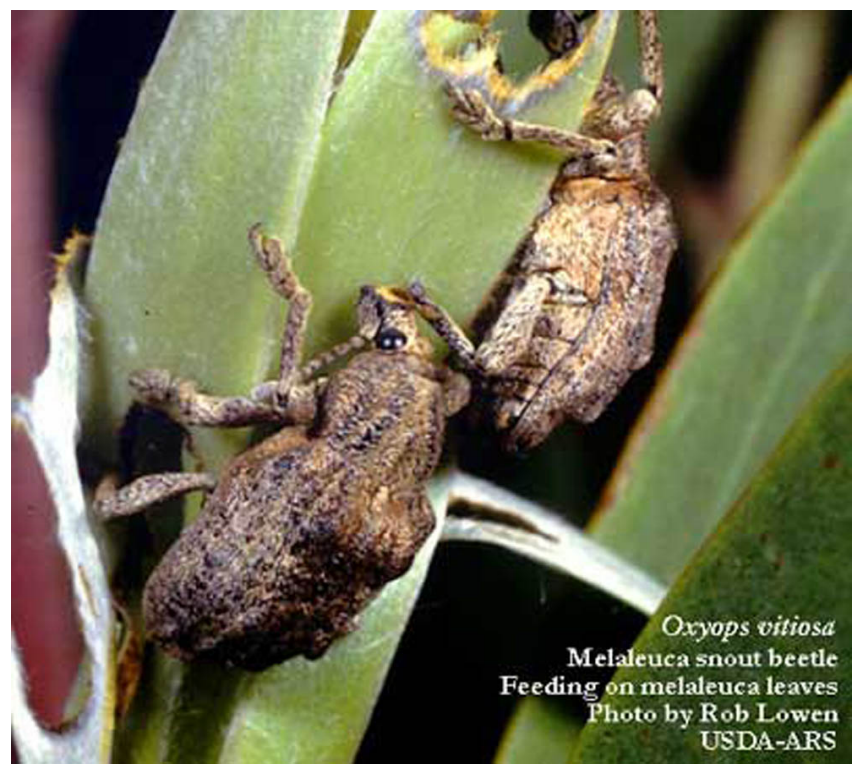

Figure 3. Two melaleuca weevil adults, Oxyops vitiosa (Pascoe), feeding on melaleuca leaves. Credits: R. Lowen, University of Florida and USDA

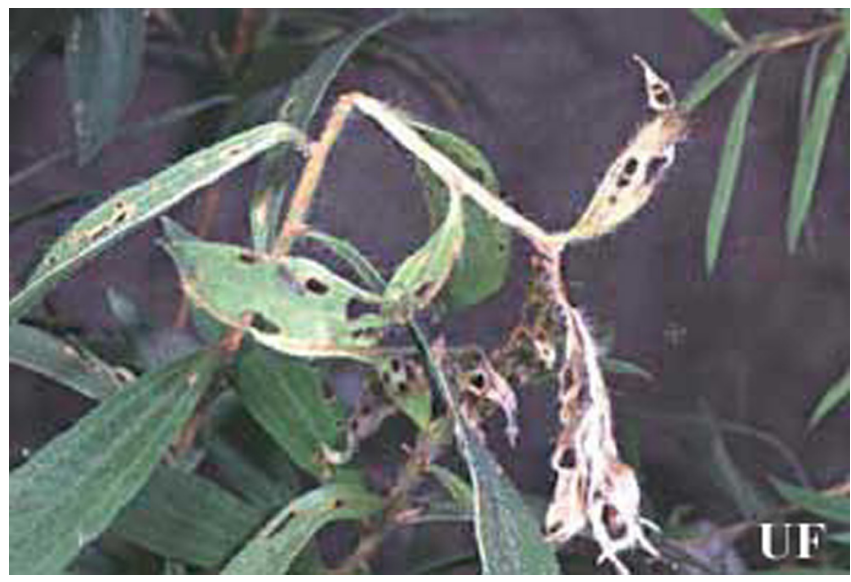

Figure 4. Excised shoot tip of melaleuca caused by adult melaleuca weevil, Oxyops vitiosa (Pascoe), feeding damage. Credits: R. Lowen, University of Florida

\section{Larva}

The larval stage has four instars, or growth phases. The appearance and size of the larvae vary depending upon their age. Neonates, or newly hatched larvae, are yellow and less than $1 \mathrm{~mm}$ long. In contrast, the mature larvae are $14 \mathrm{~mm}$ in length, grayish in color and are slug-like in appearance. Developing larvae are usually covered with translucent yellow or orange oily secretion that turns black after fecal material is incorporated into it. This oily secretion mixed with fecal matter affords the larvae protection from fire ants and possibly other predators. Larvae produce a long thin coil of feces.

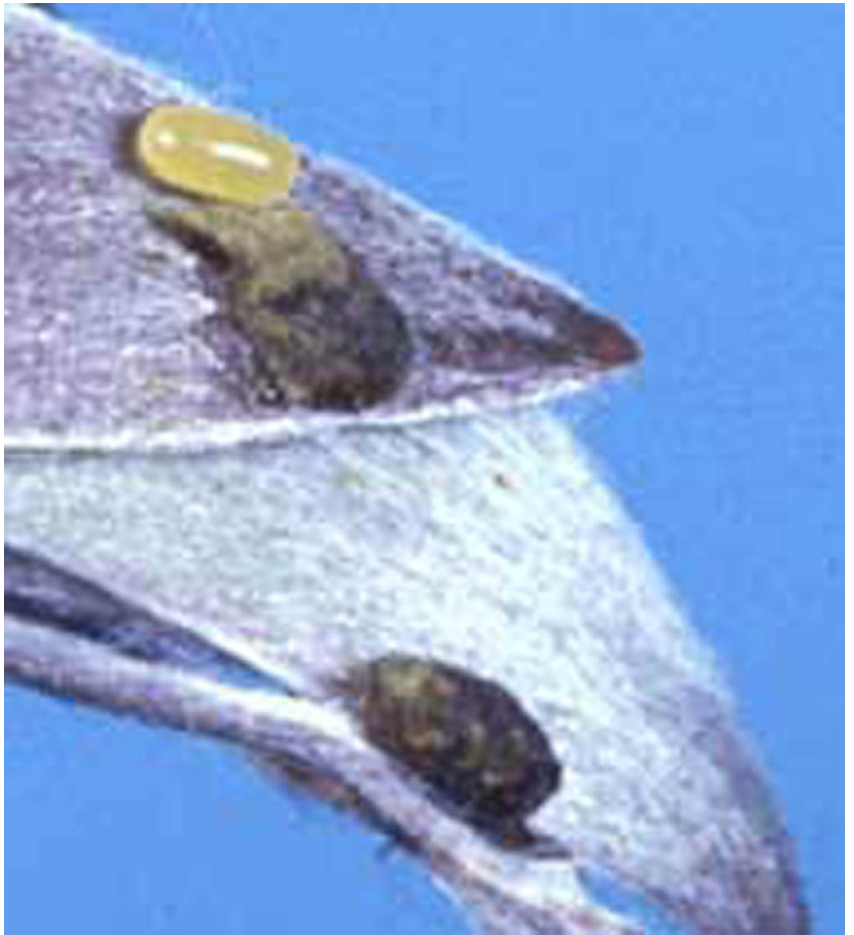

Figure 5. Eggs of melaleuca weevil, Oxyops vitiosa (Pascoe), on young leaves; uncovered (yellow) and covered with brown to black secretion. Credits: $G$. Buckingham, USDA

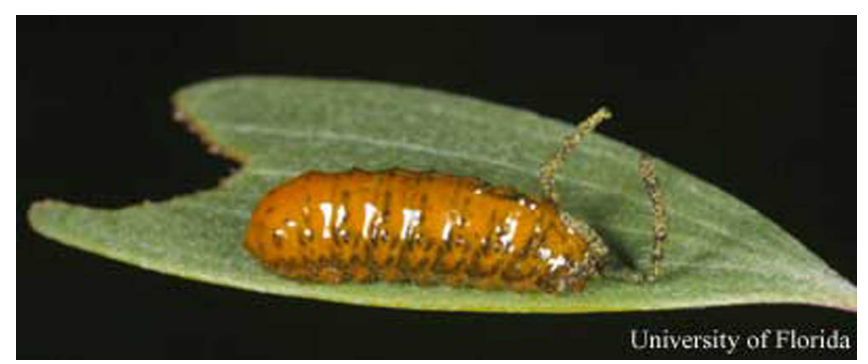

Figure 6. Larva of melaleuca weevil, Oxyops vitiosa (Pascoe), feeding on melaleuca leaf. Note fecal coil attached to larva. Credits: Lyle Buss, University of Florida

The feeding damage produced by the larval stage is very different from the adults. Instead of chewing holes in the leaves, the larvae consume all layers of the leaf except for the cuticle on the opposite side. The appearance of the paper-thin feeding trails in the leaves produced by the developing larvae is a clear indication that melaleuca weevils are present. Prior to pupation, the mature larvae, or prepupae, cease feeding and are yellow in color.

\section{Pupa}

The pupal stage is not visible because it occurs beneath the soil surface. Larvae develop to the pupal stage inside an earthen capsule formed by the 


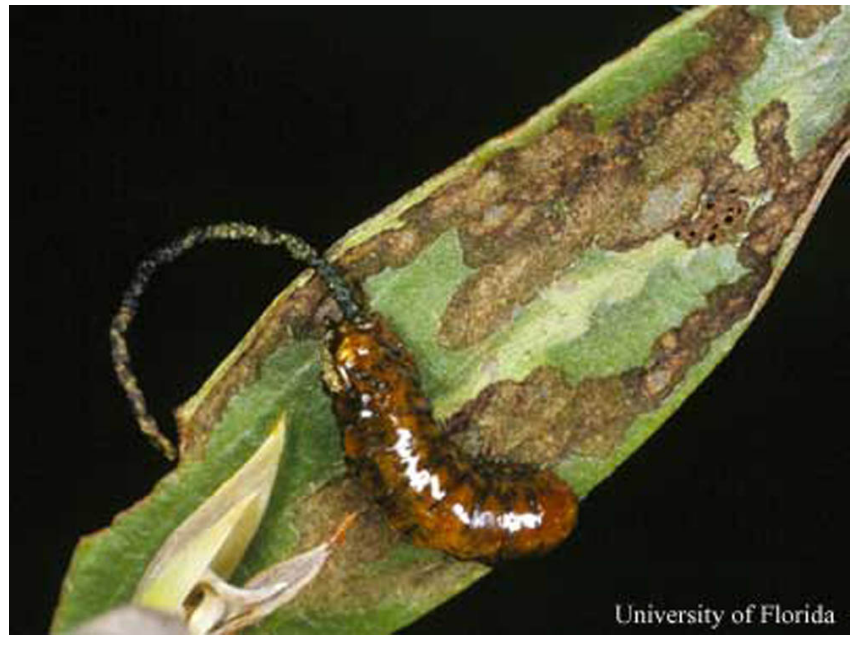

Figure 7. Melaleuca leaf showing feeding damage and larva of the melaleuca weevil, Oxyops vitiosa (Pascoe). Credits: Lyle Buss, University of Florida

prepupae. The pupal capsule, which is made of soil and an oily secretion produced by the insect, is approximately $10 \mathrm{~mm}$ in diameter. The newly formed pupae are of the exarate type (i.e. the legs and wings are free and not glued to the body), and are yellowish in color but turn brown prior to emergence of the adults from the soil.

\section{Importance}

Both adults and larvae damage melaleuca by disrupting the plant's normal growth processes. Large larvae can destroy most of the leaves on several shoots of an individual plant. At several sites in south Florida where high populations of the larvae have been observed, extensive areas of damaged melaleuca foliage are evident. Reduced flowering (up to 90\%) also has been demonstrated experimentally by USDA/ARS scientists at several sites in south Florida where the weevil is established. This type of feeding damage may help to reduce seed production and prevent further spread of this highly invasive plant.

Because the insect disperses slowly, a coordinated redistribution program is needed to establish the insect in all 22 counties in central and south Florida infested with melaleuca. A standardized procedure for collecting and transporting the adult melaleuca weevils to other sites where the weevil is not yet established has been developed and implemented in St. Lucie County.

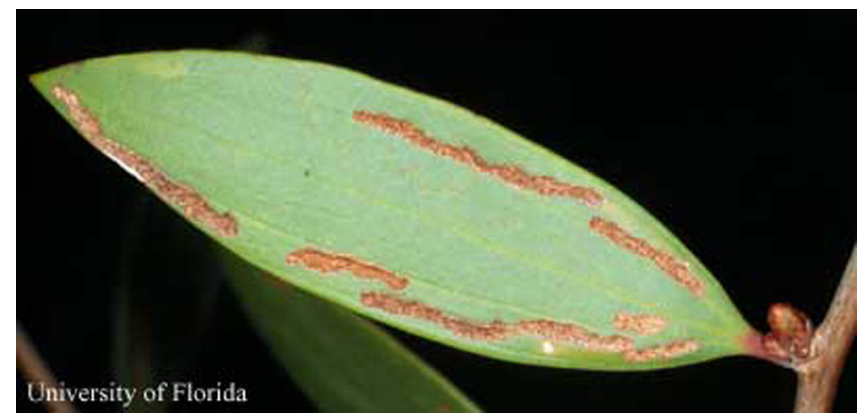

Figure 8. Melaleuca leaf showing feeding damage by the larvae of the melaleuca weevil, Oxyops vitiosa (Pascoe). Credits: Lyle Buss, University of Florida

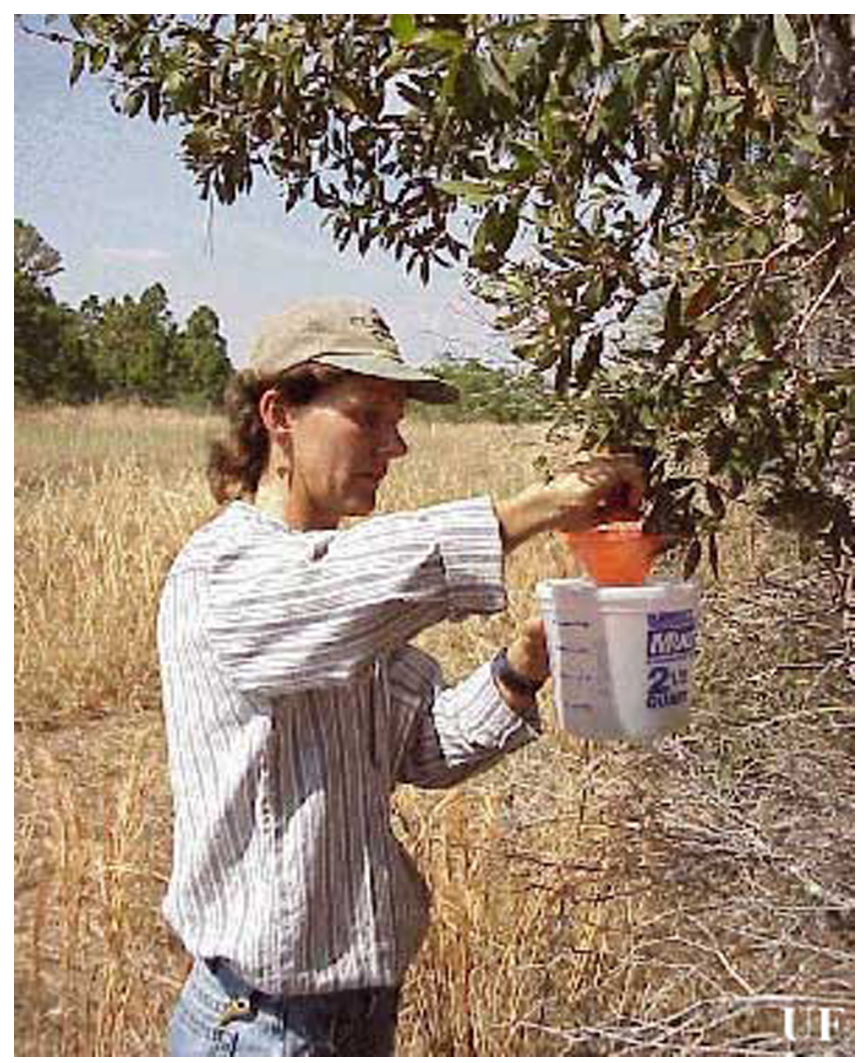

Figure 9. Procedure for collecting adult melaleuca weevils, Oxyops vitiosa (Pascoe), for redistribution. Credits: $\mathrm{K}$. Gioeli, University of Florida

\section{Selected References}

Balciunas JK, Burrows DW, Purcell MF. 1994. Field and laboratory host ranges of the Australian weevil, Oxyops vitiosa (Coleoptera: Curculionidae), a potential biological control agent for the paperbark tree, Melaleuca quinquenervia. Biological Control 4: 351-360.

Center TD. et al. 2000. Field colonization of the melaleuca snout beetle (Oxyops vitiosa) in south Florida. Biological Control 19: 112-123. 
Center TD, Dray FA, Vandiver Jr VV.

(September 2000.) Biological control with insects:

The melaleuca snout beetle. EDIS.

http://edis.ifas.ufl.edu/BODY_AG022 (May 2001).

Langeland KA, Burks KC. 1998. Identification \& biology of non-native plants in Florida's natural

areas. University of Florida, Gainesville, FL.

Purcell MF, Balciunas JK. 1994. Life history and distribution of the Australian weevil, Oxyops vitiosa (Coleoptera: Curculionidae), a potential biological control agent for Melaleuca quinquenervia (Myrtaceae). Annals of the Entomological Society of America 87: 867-873.

Wheeler GS. 2000. Sequestration of Melaleuca quinquenervia defensive chemistry by Oxyops vitiosa and its relevance to biological control of weeds, $p$. 431. In Spencer, N.R. (ed.), Proceedings of the X International Symposium of Biological Control of Weeds, 4-14 July 1999. Montana State University, Bozeman, MT.

Wineriter S, Buckingham GR. 1997. Love at first bite - introducing the Australian melaleuca weevil. Aquatics 19: 10-12. 